\title{
MAGIA E IMAGINAÇÃO: ESTUDO E DESENVOLVIMENTO DA MARCA PIXIE AROMAS
}

MAGIC AND IMAGINATION: STUDY AND

DEVELOPMENT OF THE PIXIE AROMAS BRAND

\section{Marcieli Hoffmann}

Graduada em Publicidade e Propaganda pela Univates (Lajeado/Brasil).

E-mail: marcielipp@gmail.com.

\section{Elizete de Azevedo Kreutz}

Doutora em Comunicação Social pela Pontifícia Universidade

Católica do Rio Grande do Sul (Porto Alegre/Brasil).

Professora na Univates (Lajeado/Brasil).

E-mail: eakreutz@univates.br. 


\section{RESUMO}

O ser humano usa os cinco sentidos para perceber o mundo, e o branding sensorial vem cada vez mais ganhando espaço no mercado como estratégia de evocar nossas emoções, com muito mais intensidade do que qualquer outro estímulo. O presente estudo tem como objetivo geral descrever os processos de criação e de desenvolvimento de uma marca de aromatizantes para o mercado do Vale do Taquari/RS. 0 processo de construção de marca é complexo e exige do profissional conhecimento (saber), experiência (saber fazer) e ética (saber ser). Assim, o estudo se justifica na medida em que é relevante para os profissionais da área, para os acadêmicos e também para os empresários, posto que apresenta os passos para criação de uma marca real. As metodologias adotadas foram a qualitativa exploratória, ancorada na Hermenêutica de Profundidade, e a metodologia de Construção de Marcas Mutantes. Como resultados, verificou-se que, para honrar a essência de uma marca cuja missão é despertar emoções por meio do olfato, o que exige ainda mais engajamento e interesse profundo em sentimentos humanos por parte dos profissionais responsáveis, a estratégia de criação e de desenvolvimento de uma marca mutante foi a mais adequada, e esse processo é descrito ao longo do presente artigo.

Palavras-chave: Marca. Brandsense. Estratégias. Aromas. Identidade visual mutante.

\section{ABSTRACT}

The human being uses the five senses to perceive the world and sensory branding has been increasingly gaining market space like strategy of evoke our emotions with much more intensity than any other stimulus. The present study has as general objective describe the process of creation and development of a flavourings brand for the Vale do Taquari/RS's market. The process of brand building is complex and demands of the professional the knowledge (to know), experience (know how) and ethics (how to be). Therefore, the study is justified by the relevance for professionals of the area, the academics and the entrepreneurs too, once it presents the steps for the creation of a real brand. The methodology adopted was the qualitative exploraty, anchored in Deep Hermeneutic and methodology of building Mutant Brands. As a result, it was verified that to honor the essence of a brand whose mission is to arouse emotions through smell, which requires even more engagement and deep interest in human feelings on the part of the professionals responsible, the strategy of creation and development of a changeable brand was the most suitable and this process is described over the present article.

Keywords: Brand. Brandsense. Strategies. Flavors. Mutant visual identity. 


\section{INTRODUÇÃO}

O ser humano usa os cinco sentidos para perceber o mundo e, segundo Gobé (2002), muitos estudos podem comprovar que o olfato pode evocar nossas emoções com muito mais intensidade do que qualquer outro estímulo. Com o crescente avanço nas pesquisas sobre aromaterapia, seu uso vem crescendo a cada dia, ressaltando a sua importância e influência nas emoções das pessoas.

Outrossim, muitas marcas estão investindo na sua versão olfativa, como Melissa, Starbucks e Play Doh. A razão disso pode estar vinculada à frase de Hellen Keller, citada por Lindstrom (2012, p. 96): "O olfato é um mago potente que nos transporta por milhares de quilômetros por toda a nossa vida".

Desta forma, o presente estudo tem como objetivo geral descrever os processos de criação e de desenvolvimento da marca Pixie Aromas, de propriedade de Hoffmann, para o mercado do Vale do Taquari/RS. Os objetivos específicos são: revisar os conceitos das categorias marca, branding, brandsense, aromas e imaginário; analisar o contexto sócio-histórico no qual está inserida a marca proposta; estudar as possibilidades de criação da marca (naming + identidade visual); aplicar a metodologia de construção de Identidade Visual Mutante e fazer os devidos registros para garantir sua proteção.

O processo de construção de marca é complexo e exige do profissional conhecimento (saber), experiência (saber fazer) e ética (saber ser). Assim, o estudo se justifica na medida em que é relevante para os profissionais da área, para os acadêmicos e também para os empresários, posto que apresenta os passos para a criação de uma marca real.

A metodologia adotada foi a qualitativa exploratória (GIL, 2010), ancorada na Hermenêutica de Profundidade (THOMPSON, 1995) e na metodologia de construção de Marcas Mutantes (KREUTZ, 2012). Quanto aos instrumentos metodológicos, estes foram a pesquisa bibliográfica (STUMPF, 2016), pesquisa de internet(YAMAOKA, 2016), análise de semiótica (PENN, 2002) e cliente oculto (BUENO, 2008).

$\mathrm{O}$ artigo inicia com a apresentação dos conceitos das categorias anteriormente mencionadas, à luz de autores renomados, seguido pelo estudo de caso, analisando seu contexto sócio-histórico, as possibilidades de criação, naming e identidade visual, bem como o registro de marca para, ao final, descrevermos os processos utilizados.

\section{UMA MARCA QUE FAZ SENTIDO}

De acordo com o Instituto Nacional de Propriedade Industrial (INPI), marca é "um sinal distintivo cujas funções principais são identificar a origem e distinguir produtos ou serviços de outros idênticos, semelhantes ou afins de origem diversa" (INPI, 2018, texto digital). Também menciona que "de acordo 
com a legislação brasileira, são passiveis de registro como marca todos os sinais distintivos visualmente perceptíveis, não compreendidos nas proibições legais, conforme disposto no art. 122 da Lei n 9279/96 - Lei da Propriedade Industrial" (INPI, 2018, texto digital).

Para Martins (2006), a marca demonstra a união de atributos que podem ser tangíveis ou intangíveis, simbolizados em um logotipo e que, se gerenciada corretamente, cria influência e gera valor. Para ele, um correto gerenciamento de marca faz com que ela tome proporções que ultrapassam a natureza econômica, ou seja, passa a fazer parte da cultura e gera influência sobre a vida das pessoas.

Para que a marca seja única e significativa para seus públicos, ela precisa ter um propósito. De acordo com Troiano (2017), o propósito é a resposta da pergunta "por que eu existo?" Enquanto que a visão traduz onde a organização (marca) quer chegar e a missão revela o que ela sabe fazer bem, o propósito entra como a resposta do porquê. E a definição do propósito serve como uma inspiração para crermos em algo maior (REYMAN, 2013). Dessa forma, entende-se que quando a marca sabe o porquê da sua existência, o que faz bem e onde quer chegar, o objetivo se torna mais claro. E isto é fundamental para alcançá-lo.

Kotler (1992) afirma que, desde que bem elaborada, a missão proporciona aos colaboradores da empresa um senso de direção. Uma declaração de missão estratégica mostra aos colaboradores seu caminho e para qual propósito devem trabalhar. Para o autor, as declarações de missão são melhores quando orientadas pela visão, que é um sonho difícil de realizar e que mostrará o caminho para os próximos anos.

Levando em consideração a globalização e o crescente aumento da competição por parte das marcas, Kreutz e Más Fernández (2009) concluem que as empresas têm a necessidade de criar e gerenciar adequadamente seus ativos tangiveis e intangiveis para crescer em uma perspectiva de prazo mais longo. Para isso, são adotadas estratégias de branding que, devido à limitação do artigo, serão abordadas em profundidade em estudo futuro do objeto.

Rodrigues (2013) define branding como a construção e a administração da marca, fazendo uso de todos os pontos de contato com seu público. Assim, é feito um gerenciamento das associações e interesse dos públicos pelas marcas, seja ela uma organização, pessoa, produto, serviço ou outros.

Uma marca deve se transformar em algo muito além do que podemos ver ou tocar, deve ser algo que podemos sentir, conforme Lindstrom (2012). Para o autor, a experiência do cliente com a marca deve ultrapassar os limites do consciente, teoria que vai ao encontro das palavras de Kreutz (2012, p. 1), que define marca como uma "representação simbólica multissensorial, cujos significados são construídos socialmente por meio de discurso multimodal".

Muitos autores, como Gobé (2002 e 2010), Lindstrom (2012), Farkas (2013) e Kreutz (2009 e 2012), concordam que a adoção de estratégias sensoriais é o futuro das marcas e, para isto, é necessário escutar 
as pessoas para criar uma forte conexão com elas para, desta maneira, apresentar melhorias em seus mundos (GOBÉ, 2002).

De forma instintiva, costuma-se ignorar a maior parte das propagandas que chegam por meio das mídias tradicionais. Segundo Farkas (2013), o indivíduo bloqueia sua mente ao bombardeio de apelos visuais e auditivos, mas reage bem a estímulos agradáveis e motivadores, como os aromas, cuja reação é "praticamente instantânea: as emoções afloram e a mágica acontece" (FARKAS, 2013, p. 78).

O estudo Brandsense de 2005, realizado por Lindstrom (2012), concluiu que o cheiro e a aparência ocupam a mesma classificação na escala de importância dos consumidores, sendo o olfato o segundo sentido mais importante, somando $23 \%$ das respostas, perdendo apenas para a visão, com $37 \%$. Para ilustrar a situação, Lindstrom (2012, p. 9) cita que "cada pedaço de fruta e corte de carne que entram em nosso carrinho de compra passam pelo teste do nariz".

Os aromas passaram a ter uso proposital em ritos religiosos do hinduísmo, cristianismo, mitologia grega e africana, por volta de 700 a.C. Na época, segundo Farkas (2013), as plantas eram associadas aos deuses de acordo com seu perfume, forma e propriedades curativas. As iguarias aromáticas também já eram utilizadas na culinária e cosmética, fazendo parte do dia a dia dos ancestrais.

A autora afirma que, ao inalarmos um aroma, ele leva cerca de 15 segundos para chegar no sistema límbico, local do cérebro onde estão alojados as memórias, os impulsos sexuais, as emoções, o aprendizado e os instintos. Em seguida, ele chega na hipófise, uma glândula que transfere os dados para outras glândulas do corpo, o que acarreta em alterações hormonais e no ritmo cardíaco e respiratório. Isso explica por que ao sentir um aroma tem-se reações e lembranças.

O aroma não é filtrado pelo cérebro, por isso, pode-se afirmar que o nariz é um elo direto com as memórias e emoções (GOBÉ, 2002). Ao incorporar um aroma em sua identidade, a marca provoca determinadas sensações e reações em seu público.

Dessa forma, os aromas despertam emoções e alimentam a imaginação. Lindstrom (2012) defende que quanto mais mística a marca cultivar em seu comportamento, mais cresce a chance de se tornar um produto procurado e admirado. Nesses casos, a relação da marca com os arquétipos é relevante.

Os arquétipos são formas ou imagens de conhecimento coletivo, componentes de mitos, usados como ideias elementares que oferecem suporte na sustentação de comportamentos e discursos de marca (MARK; PEARSON, 2017). Para as autoras, não se trata apenas de usar um símbolo ou imagens, mas de se apropriar do perfil do arquétipo ao posicionar a marca, para que assuma significação simbólica. Tudo o que for feito em relação à marca deve reforçar aquele arquétipo, a fim de sustentar a organização e a padronização de comportamentos, do seu discurso multimodal (SILVESTRE et al., 2009), que é responsável pela sua imagem-conceito (BALDISSERA, 2003). 
De acordo com Silvestre et al. (2009), o discurso multimodal da marca são todos os seus atos sociais, os quais traduzem sua essência: o naming, identidade visual, anúncios, website, entre outros, incluindo ainda a versão olfativa da marca, objeto deste estudo.

Esse comportamento global de marca, que gera experiências e percepções em seus públicos, é que constituirá a sua imagem-conceito. Para Baldissera (2003, p. 6):

[...] a imagem-conceito sempre é uma construção mental, realizada pelos sujeitos em relação com o entorno e consigo mesmos, tendo como base a comparação e a valoração (...). Para isso, a pessoa/público associa, compara, sobrepõe, hierarquiza as informações que recebe/acessa, oficiais ou não, com os seus saberes prévios, isto é, com as condições de produção a partir do lugar que cada indivíduo/público assume no sistema sociocultural.

A construção de marca, portanto, parte de sua essência, avança pelo seu propósito, pela análise do que a marca é e também do que ela não é, de seus públicos, de seus pontos fortes, fracos, oportunidadese ameaças. Além disso, deve analisar o mercado e seus concorrentes, entre outros aspectos de seu contexto complexo. Essas análises são necessárias porque a marca é um negócio, mas antes de tudo ela deve gerar a identificação em seus públicos para obter sucesso enquanto negócio.

As marcas têm a necessidade de conhecer os grupos que a influenciam e saber o que acontece entre eles, a fim de entender a melhor forma de chegar em seu público. Para Kotler (1992, p. 87), a organização precisa estar sempre monitorando as forças macro e microambientais que possam influenciar nos seus negócios. Ele define macroambientais como as forças de origem "demográficas, econômicas, tecnológicas, políticas, legais, sociais e culturais" e microambientais como "consumidores, concorrentes, canais de distribuição, fornecedores".

Para o autor, a unidade de negócio deve sempre estar atenta às tendências do mercado, desenvolvendo um sistema de inteligência de marketing. Por meio deste sistema, para cada tendência se deve identificar oportunidades e ameaças a ela relacionadas. Como vimos, a marca é mais do que seu naming e sua identidade visual. Contudo, são estes os elementos passíveis de registro no INPI.

Para Rodrigues (2013, p. 18), "o nome revela em parte a origem da marca, e dessa forma também sua identidade". Já para Keller (2006), muitas vezes o nome indica de forma direta a qual produto está associado, sendo uma escolha de importância fundamental, e pode ser um meio de comunicação breve e efetivo. Para ele, o ideal é que a marca tenha significado claro e não deve ter significados pejorativos em outras linguagens. 
Para Neumeier (2008), alguns critérios devem ser respeitados para a escolha de um bom nome: distinguibilidade (capacidade de distinguir a marca); brevidade (nomes curtos para serem lembrados); conveniência (nome ajustado ao propósito comercial da empresa); grafia e pronúncias fáceis; agradabilidade (tem de ser agradável ao público-alvo); extensibilidade (possibilidade de adequação a diversas finalidades) e possibilidade de proteção (aspectos legais do uso do nome).

Rodrigues (2013) sugere a classificação dos nomes de marcas como sendo:

1. Nomes Patronímicos: baseados em nomes de pessoas.

2. Nomes Descritivos: descrevem a natureza do negócio.

3. Nomes Toponímicos: remetem ao lugar de atuação ou origem da marca.

4. Nomes Metafóricos: revelam a natureza do negócio de forma indireta.

5. Nomes Artificiais: engloba os neologismos, palavras novas que não existem no dicionário.

6. Abreviações: ocorre quando os nomes das empresas são grandes demais para serem ditos inteiros.

7. Nomes de Status: nomes que, pela sonoridade, remetem a condições de status.

O desenvolvimento de um nome para a marca é um dos mais importantes passos na criação e exige uma série de etapas ordenadas e revistas por Rodrigues (2013). A primeira etapa é o briefing, que contém as informações necessárias para conhecermos a marca, como fundador, história, situação financeira, públicos e outros. Por meio dele, juntamente com pesquisas complementares, podemos conhecer profundamente a marca em questão, para que se possa identificar seu posicionamento, público, conceitos e posição no mercado.

No que diz respeito à criação e ao desenvolvimento de Identidade Visual, Kreutz (2001) afirma que as principais estratégias de construção são: Estereotipada, Arbitrária e Mutantes. Segundo Kreutz (2005), as Marcas Mutantes, enquanto identidades visuais (IV), podem ser Programadas ou Poéticas. As Programadas são as IVs que têm limites em suas variações, que ocorrem também por tempo determinado. Já as Mutantes Poéticas são marcas cujas variações de suas IVs ocorrem de forma espontânea e sem obedecer a regras pré-determinadas, apenas à criatividade do designer.

Para a construção de uma IV Mutante, Kreutz (2012, p. 4) sugere seguir sete fases, considerando "as informações básicas quanto à organização (seus valores, cultura e objetivos), ao público (seus valores culturais e econômicos, repertório) e às questões técnicas, semânticas, persuasivas e interativas". Um bom desenvolvimento da identidade visual desperta o imaginário do público, fazendo com que interaja com a marca de forma positiva. A metodologia proposta pela autora é a seguinte: 
1. identificar a natureza/essência da organização;

2. determinar a percepção de marca desejada;

3. considerar as características desejáveis;

4. determinar o naming + identidade visual base (IVB);

5. características mutantes;

6. as coleções de IVM;

7. campo interativo.

\section{CONSTRUINDO UMA IDENTIDADE VISUAL MUTANTE}

Considerando o exposto, para a criação e o desenvolvimento de uma marca dedicada ao segmento olfativo, considerando que o briefing já foi realizado, o primeiro passo foi realizar a análise de mercado, a qual foi desenvolvida no período de agosto de 2017 a junho de 2018, no Vale do Taquari, nos municípios de Lajeado, Arroio do Meio, Bom Retiro do Sul, Santa Clara do Sul e Cruzeiro do Sul. O instrumento utilizado foi cliente oculto (BUENO, 2008), sendo necessária mais de uma visita em cada estabelecimento comercial para avaliar a evolução do mercado. Para preservar a identidade das marcas selecionadas, optou-se por nomeá-las de Marca 1, 2, 3 e 4, e os resultados são apresentados de modo sucinto.

A Marca 1 garante ao consumidor qualidade e durabilidade nos produtos. Afirma trabalhar com aromas naturais, que têm um custo mais elevado e podem ser usados em tratamentos com aromaterapia. Contudo, não justifica os baixos preços praticados com relação ao produto oferecido, o que indica uma incongruência da marca que poderá ser relativa à qualidade de seus produtos ou à má-administração financeira. É uma empresa com pouco mais de uma década no mercado, com fábrica própria e com um significativo número de funcionários, o que indica que cresceu muito rapidamente. Em seu ponto de venda, oferece um limitado leque de opções de aromas, sintetizados nas formas de difusores em spray, gessos, sachês, difusores de varetas, esculturas em madeira perfumadas, envelopes aromáticos e outros.

Embora a marca se posicione como especialista em aromaterapia, novamente transparece a incongruência na medida em que a aromaterapia só funciona com o uso de óleos essenciais naturais e não com essências sintetizadas artificialmente, que fazem uso em seus produtos. O que se percebe é uma atitude de brandwashing que, de acordo com Lindstrom (2012), ocorre quando uma marca ludibria o consumidor.

Além disso, as vendedoras têm pouco domínio sobre a aromaterapia, sendo necessárias a consulta e a entrega de um folheto para o cliente entender os benefícios da maioria dos aromas. A marca tem preferência por comercializar seus produtos nos próprios pontos de venda (PDV), garantindo a exclusividade e facilitando o direcionamento ao público-alvo. 
A Marca 2 concentra seus esforços na decoração de frascos para exposição, chegando a vendêlos vazios a preços justos, tendo em vista o trabalho manual. Seus aromas são de significativa baixa duração, se comparados aos da Marca 1, e seu menu de aromas é pequeno, sendo eles traduzidos em linhas criativas de difusores. Os aromas são comercializados em forma de spray para ambientes, água de lençóis, difusores de varetas, óleos para difusores elétricos, sachês, envelopes aromáticos e outros. Em sua maioria, os aromas não se encontram dentro dos frascos decorados, sendo necessária a compra separadamente. A marca possui uma identidade visual atraente para cada uma das linhas criativas, sendo o PDV luxuoso e iluminado.

A atendente da loja demonstrou pouco domínio sobre aromas e concentrado domínio sobre trabalhos manuais. Seus produtos são de baixo custo e são comercializados em várias lojas terceirizadas do Vale do Taquari, possuindo apenas um PDV exclusivo na cidade de Lajeado. Ao visitar as lojas revendedoras, foi constatada a falta de padrão na exposição e nos valores dos produtos. Em um caso isolado, uma mesma loja comercializa produtos de três marcas concorrentes diferentes, além de artigos de decoração, alimentos e acessórios. A prática é imprópria para a marca, pois foge do fornecedor o controle dos valores e a exposição do produto, podendo ele ser concorrente dos seus próprios revendedores, colocando em risco o posicionamento da marca, bem como de sua imagem-conceito.

A Marca 3 possui 20 franquias divididas em cinco estados brasileiros, além de revendedores (pessoa física) por todo o Brasil. Possui fabricação própria dos materiais comercializados, sendo o ponto de venda elegante e sofisticado. As vendedoras têm domínio sobre o produto que vendem e estão uniformizadas de acordo com a identidade visual da marca. Seus produtos têm uma vasta quantidade de submarcas. Em seu leque de produtos possui, além dos comercializados pelas marcas concorrentes acima citadas, itens voltados para o setor da cosmética, como shampoos, cremes hidratantes e sabonetes.

A marca 3 também produz cosméticos para outras marcas. Suas vendas são efetivadas em pontos de venda que respeitam a imagem da marca, com vendedores uniformizados e capacitados para tal. A incoerência da marca se revela quando libera a venda para qualquer pessoa física, que, com a autorização da marca, compra uma grande quantidade de produtos a um preço reduzido para revenda. Tal prática vai ao encontro das observações feitas para a Marca 2, cuja imagem-conceito corre riscos pela falta de controle do seu discurso multimodal.

Já a Marca 4, por sua vez, tem fabricação própria para vender em mercados terceiros. A empresa não possui loja própria, eliminando custos com manutenção de PDV, e seus produtos são expostos em lojas de artesanato, armarinhos, artigos para festas e outros mercados. Produzem, em seu leque de produtos, envelopes aromatizados, sprays de ambiente, difusores de varetas, difusor elétrico, água perfumada para tecidos e spray de aromas automotivos. 
Em comparação à maioria das marcas analisadas, a Marca 4 não se mostra diferente, pois pratica formas de venda que ferem sua imagem. Outra característica da marca é que ela não produz apenas para si, mas terceiriza produções para outras marcas.

Por meio desta análise, comparando as quatro principais concorrentes presentes no mercado do Vale do Taquari, percebe-se que apenas uma marca valoriza a sua imagem-conceito. Também se nota a constante necessidade de vender a qualquer custo, ignorando as imagens das marcas e seus princípios, o que, nestes casos, faz-se pensar em quatro possibilidades:

1. a dificuldade financeira em manter uma empresa desse porte;

2. a grande procura pelo consumidor (demanda);

3. a necessidade de tornar a marca conhecida, mesmo que isso custe seus princípios e sua imagemconceito positiva;

4. falta de conhecimento a respeito do branding.

Para construir marcas é preciso conhecer a sua essência, pontos fortes e fracos, oportunidades, entre outros, para traduzi-la em naming e identidade visual, conforme mencionado anteriormente. 0 conceito de Identidade Visual Mutante (IVM) é recente e poucos autores falam a respeito. Segundo estudo publicado por Kreutz (2011), pesquisas mostram que o Brasil é considerado o país mais descontraído do mundo, sendo o principal motivo para as Marcas Mutantes serem bem recebidas aqui, com relação a outros países.

Considerando a marca em estudo e a metodologia para criação de Marcas Mutantes, a essência da marca em estudo é ajudar a despertar memórias olfativas das pessoas, oferecendo experiências sensoriais memoráveis no PDV, permitindo a personalização dos aromas de acordo com o briefing que será previamente coletado do cliente, o qual conterá informações sobre ele, como cores a que associa determinadas emoções ou pessoas, local onde possivelmente ficará exposto o aroma, qual o ambiente da casa que gosta mais, alimentos preferidos e famílias aromáticas com as quais tem mais afinidade. Dessa forma, será possivel conhecer melhor o cliente para, assim, se chegar na identidade olfativa mais adequada a ele.

A percepção desejada é um ambiente mágico, onde o cliente esqueça por determinado tempo o mundo em que vive e se permita imaginar e sentir o que quiser. A marca também trabalhará com linhas criativas de aromas de momentos tradicionais, a exemplo das estações do ano e das emoções, utilizando um naming de produto diferenciado, provocando sensações e memórias de outrora.

Por meio da pesquisa, verificou-se que o uso dos aromas para os mais diversos fins é feito desde os primórdios da evolução humana, porém, recentemente, as marcas começaram a investir na sua 
versão olfativa. Do ponto de vista corporativo, existem muitos estudos, como o de Lindstrom (2012), que comprovam que o uso dos aromas exclusivos e personalizados nas marcas está se tornando cada vez mais eficiente e procurado por elas, porém existem poucas marcas que investem em aromas personalizados para pessoas. A proposta inovadora da marca em questão é oferecer esse serviço aos seus usuários de forma personalizada, além de linhas criativas de aromas que provoquem memórias da infância e outros determinados momentos em comum da vida das pessoas.

A segunda etapa proposta por Rodrigues (2013) é a linha criativa, para a qual existem duas possibilidades. Uma delas é o brainstorming, que é como uma chuva de ideias para se chegar a um nome diferente, porém, de "qualidade discutivel, tendo que depois separar o joio do trigo" (RODRIGUES, 2013, p. 99), em outras palavras, ser remodelada e lapidada até chegar a um resultado. A outra linha é chamada pelo autor de "imersão", sendo descrita como uma análise profunda da marca e do que ela propõe para se chegar a um denominador comum. Essa última foi adotada pela marca em questão, por ser a que mais se identificou com a proposta oferecida por ela.

Os aromas, conforme Lindstrom (2012) e outros autores, despertam memórias e desejos. A criatura mitológica responsável pela realização dos desejos é o Mago, assim como as fadas. Aos olhos de Mark e Pearson (2017, p. 161), uma das características mais marcantes do arquétipo do Mago é fazer as coisas acontecerem através das leis que governam o funcionamento das coisas, sendo que "o marketing do Mago começa com o conhecimento daquilo que você acredita".

Por meio de pesquisas sobre mitologia, descobriu-se que Pixies são como pequenas fadas, apesar de fadas e pixies serem dois seres mitológicos diferentes, segundo a definição de Sabrina (2016). Esses seres mitológicos trabalham com ouro, prata e bronze e alguns acreditam que o resíduo destes materiais gera o principal ingrediente do pó de fada (pixie dust), o pó mágico que, na ficção, é usado para fazer com que os desejos se tornem realidade.

Baseando-se na classificação de Rodrigues (2013), o nome Pixie Aromas se encaixa na classe de Nomes Metafóricos, que são aqueles que revelam indiretamente a natureza do negócio, neste caso, a missão, que é despertar desejos. 


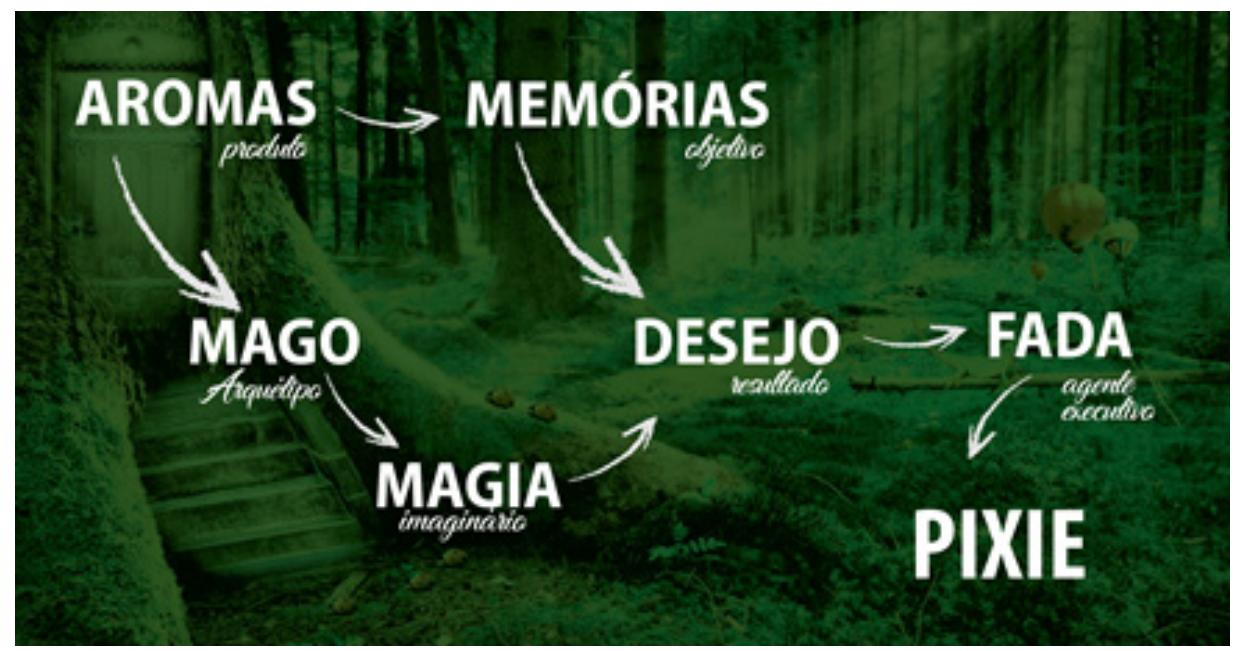

Fonte: Marcieli Hoffmann (2018)

Segundo Biedermann (1994), as pixies são frequentemente representadas com asas de borboleta, que é o símbolo da longevidade, beleza e metamorfoses sofridas em nossas vidas. Esse princípio ajuda a tecer a história de que fadas são seres humanos evoluídos, exemplos de beleza e longevidade, que, dotados de mente pura e sã, têm dons sobrenaturais, capazes de realizar desejos, de acordo com o senso comum.

Para o autor, "[referindo-se aos contos de fadas] The cosmology that prevails in these stories is that of 'a different reality; we find ourselves in the world of symbols, characteristic images each of which has special significance within it"1 (BIEDERMANN, 1994, p. 124). Tal citação vai ao encontro do propósito da marca, visto que o autor concorda que os contos de fadas podem nos colocar em uma realidade diferente da qual se está inserido.

A terceira etapa, proposta por Rodrigues (2013), é a análise do nome escolhido e a viabilidade para registro. Ao verificar a disponibilidade de registro da marca Pixie Aromas no INPI, o resultado foi de que o nome se encontra disponivel para registro. Já no Registro.br, após verificar sua disponibilidade, o registro foi realizado imediatamente, conforme mostram as figuras 2 e 3 :

\footnotetext{
1 Tradução livre: "A cosmologia que prevalece nessas histórias é a de uma 'realidade diferente'; nos encontramos no mundo dos símbolos, imagens características, cada uma delas com um significado especial dentro dela".
} 
Figura 2 - Consulta de nome e registro no site Registro.br

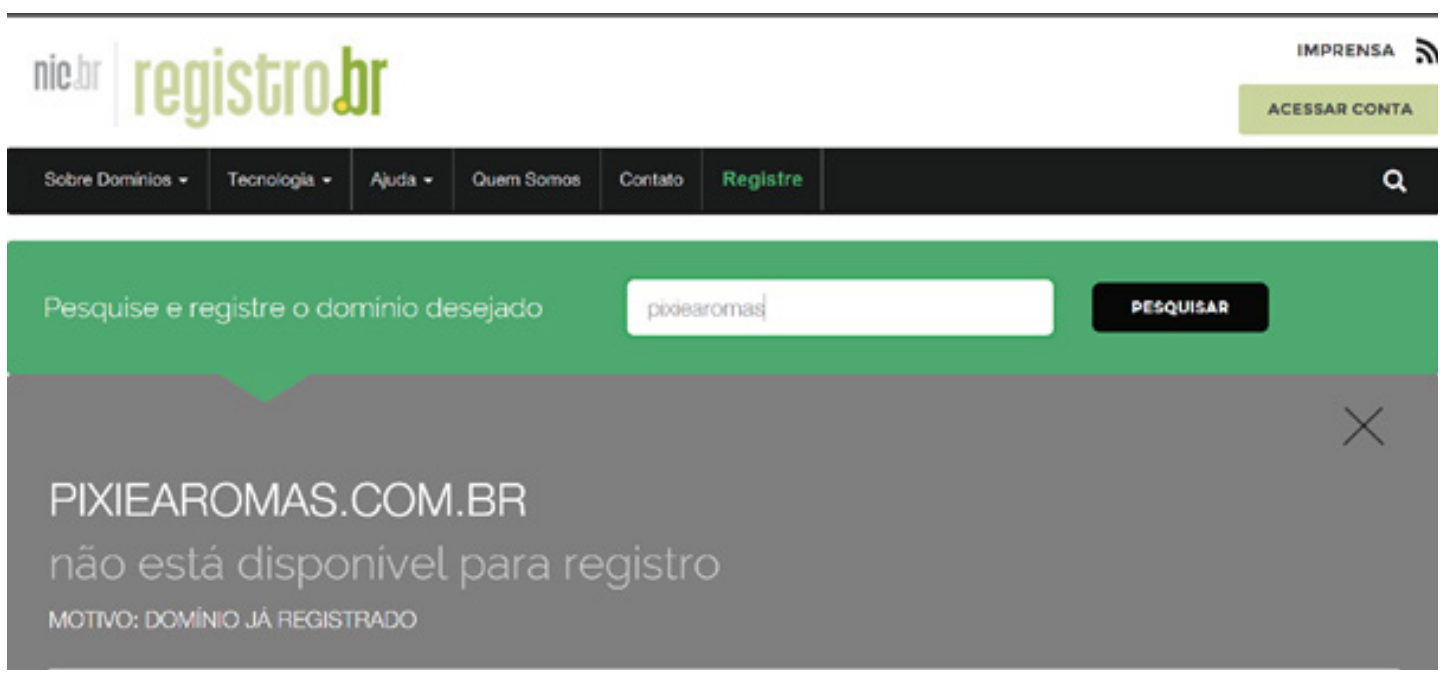

Fonte: Registro.br pesquisa Pixiearomas (2018)

Figura 3 - Consulta de nome e registro no INPI

\begin{tabular}{|c|c|c|c|c|c|}
\hline (2) BRASIL. & Acesso à informaçăo & Participe & Serviços & Legislação & Canais \\
\hline
\end{tabular}

Consulta à Base de Dados do INPI

- Consutar por: Pesquisa Bassica | Marca | Titular | Cod. Figura ]

RESLITADO DA PESQUISA (05/09/2018 às 12:33:11)

Marca: pixic aromas

- Nenhum resultado foi encontrado para a sua pesquisa. Para efetuar outra pesquisa, pressione o botão de VOLTAR.

AVISO: Depois de fiarer uma busca no banco de dados do INPI, ainda que os resultados possam parecer satisflatórios, nâo se deve concluir que a marca poderá ser registrada. O INPI no momento do exame do pedido de registro realizará nova busca que scrá submetida ao exame técnico que decidirá a respeito da registrabilidade do sinal.

Dodos atualizados até 04/09/2018 - No da Revista: 
A marca Pixie Aromas poderá ser registrada no INPI como uma marca nominativa, posto que o naming é o que prevalece nas mutações da marca. Cabe lembrar que a Lei 9279, datada de 14 de maio de 1996, determina a concessão de patentes, desenho industrial, registro de marca, entre outros benefícios, conforme o site do Planalto (2018). Entretanto, ela não assegura direitos para marcas olfativas, gustativas e sonoras. Dessa forma, concluímos que, no Brasil, o registro de aromas, sabores ou sons não pode ser feito. Em ressalva, o processo ou a fórmula podem ser protegidos por patente e a forma do frasco pode ser protegida como desenho industrial ou como marca tridimensional, conforme relata Rodrigues (2013). Outra maneira interessante de proteger a marca é usando o exemplo da gigante Coca-Cola, que mantém sua fórmula secreta desde que foi criada.

Segundo a World Intellectual Property Organization (2018), um requisito que deve ser respeitado no registro de uma marca é o de que o odor não se derive da natureza do produto, como registrar o aroma de alecrim para o próprio alecrim, produzido por uma marca. No site, encontra-se o exemplo das bolas de tênis com aroma de grama recém-cortada como um aroma registrável. Sendo assim, embora não haja nenhuma cláusula protegendo determinadas situações no Brasil, devemos estar atentos às possibilidades alternativas de proteção.

Determinado o naming de marca, é preciso traduzir, graficamente, a sua essência. A Identidade Visual Base (IVB) é a representação gráfica do que a marca representa. Para Kreutz (2012), ela é o esqueleto que servirá de base para as mutações e é registrável no INPI.

A IVB da marca Pixie Aromas deve transmitir seu significado, que é despertar o lado imaginativo e memorável das pessoas. Para a escolha da fonte selecionou-se a familia de fontes que tivesse uma boa legibilidade. Assim, para melhor ilustrar a proposta da marca, escolhemos a fonte Angleterre Book, criada pela Digital Graphic Lab. Segundo informações obtidas no site Fonts2u (2018), a fonte é da família Latin, subfamília Normal Sans e possui a licença True Type, que se caracteriza por ter a maioria de suas fontes gratuitas ou muito baratas. De acordo com o site Design Culture (2018), a licença foi criada nos anos 1980 pela Apple e posteriormente implementada no Windows 3.1 pela Microsoft. São muito recomendadas quando se faz necessário o uso de uma fonte leve e que tenha boa resolução para impressão. 
Figura 4 - Fonte escolhida para representação de logotipo

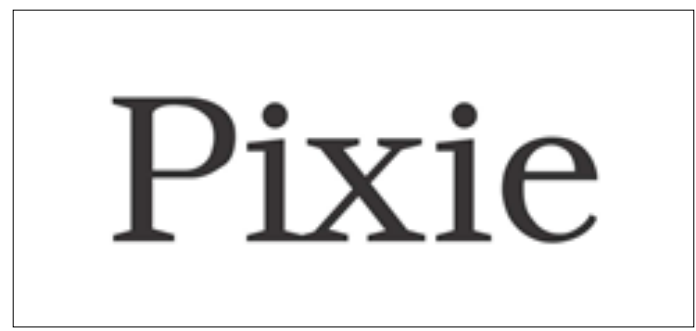

Fonte: Marcieli Hoffmann (2018)

Para dar mais originalidade à forma, foram acrescentados detalhes às letras, que, segundo Saltz (2010), podem atribuir ainda mais significação ou tornar o design mais adequado para a mensagem. No caso, realizou-se o arredondamento dos cantos da fonte, bem como a adaptação da letra $X$, para que ganhasse mais destaque em meio à palavra.

Figura 5 - Detalhamento

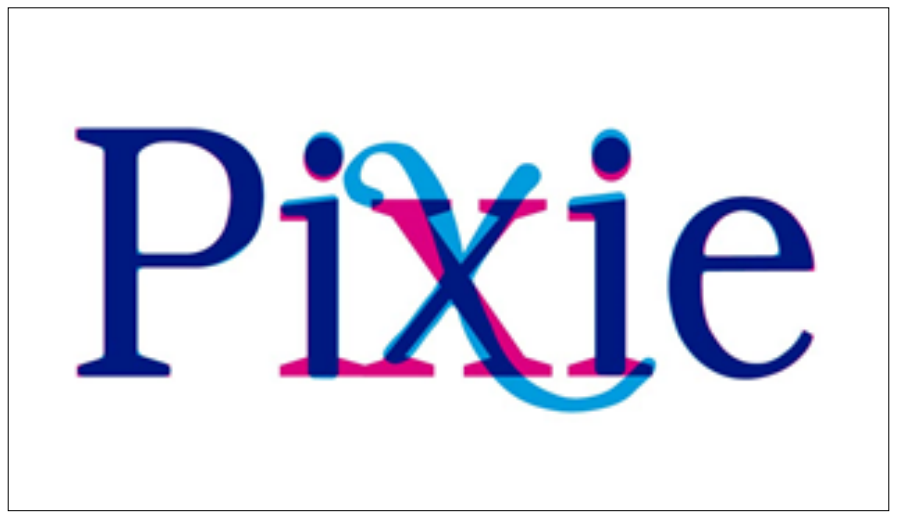

Fonte: Marcieli Hoffmann (2018)

Ajustes de kerning também foram necessários na fonte, para que a sensação de envolvimento aumentasse ao eliminar a maior parte dos espaços vazios. Cada letra de um tipo tem sua própria largura, "mas os sistemas de composição computadorizados podem modificá-la de muitas maneiras" (BRINGHURST, 2005, p. 43). 
Figura 6 - Ajustes de Kerning

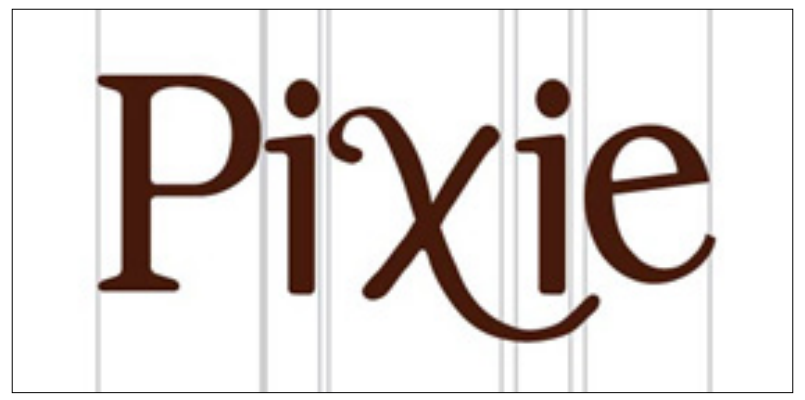

Fonte: Marcieli Hoffmann (2018)

A fim de ressaltar a essência principal da marca, em anexo ao logotipo está um símbolo que lembra uma asa de borboleta. A escolha das folhas no formato apresentado se justifica na medida em que representa três elementos em uma só unidade: fada, borboleta e natureza. As fadas são representadas pelas borboletas e ambas se encontram na natureza. Biedermann (1994) define borboletas como simbólicas tanto pela metamorfose como pela natureza transitória de felicidade. Para o antropólogo, devido ao grande sofrimento que a borboleta tem durante as metamorfoses em seu curto período de vida, ela é considerada uma fonte de esperança e até ressurgimento da vida, considerando a alma como eterna. As cores usadas na marca-base foram preto e branco. Já as mutações serão criadas de acordo com o ambiente de aplicação da marca. 
Figura 7 - logotipo + ícone

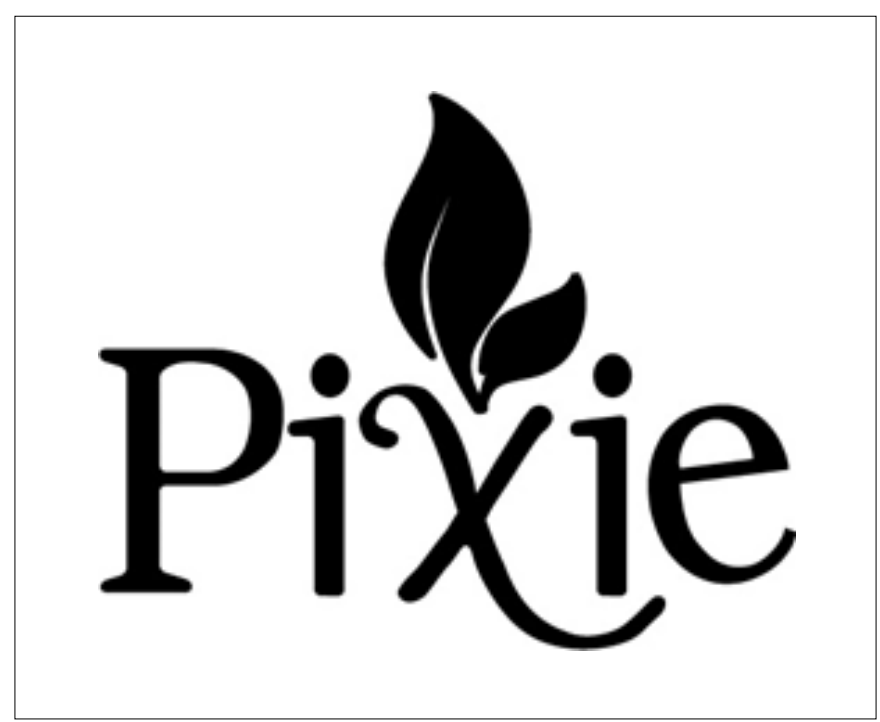

Fonte: Marcieli Hoffmann (2018) 


\subsection{PROPOSTA DAS COLEÇÕES}

Foram selecionadas algumas coleções, baseadas em datas comemorativas, elementos místicos e da natureza, em que a marca possa sofrer mutação, para que sirvam de ilustração à proposta.

\section{Datas comemorativas}

Para ilustrar essa coleção, foram escolhidas algumas datas comemorativas relativas à natureza e à mística.

\section{Estações do ano}

Para dar vida a esta coleção, utilizou-se elementos presentes em cada estação. A figura 8 ilustra a estação da primavera.

\section{Figura 8 - Estações do ano}

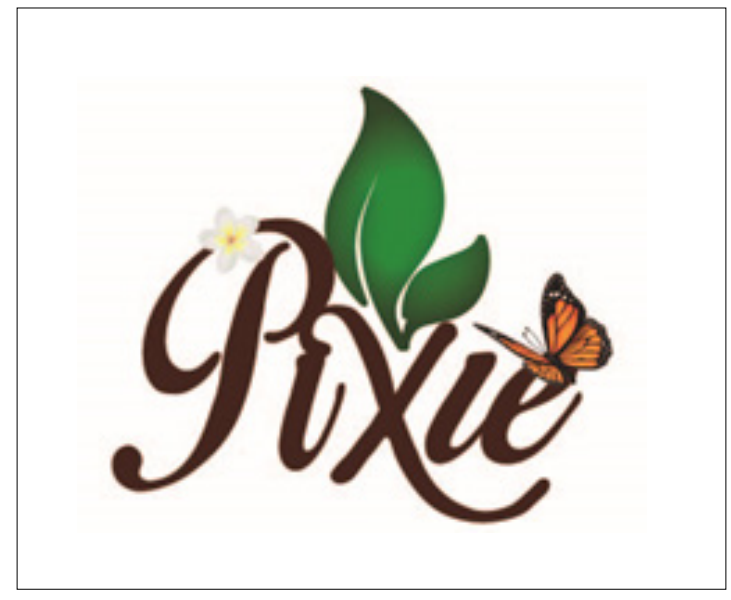

Fonte: Marcieli Hoffmann (2018) 


\section{Natal}

O Natal é considerado, por muitos, a data comemorativa mais esperada do ano, pois representa o nascimento e a renovação da vida. Para ilustrar essa data, a folha foi substituída pelo gorro do principal personagem desta data, o Papai Noel.

Figura 9 - Natal

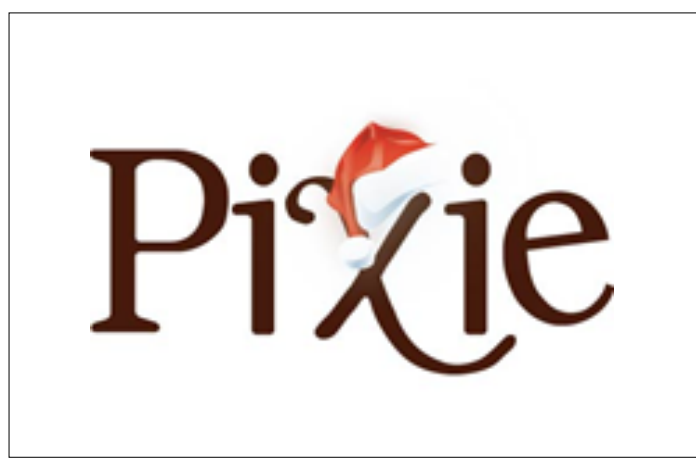

Fonte: Marcieli Hoffmann (2018) 


\section{Dia das Bruxas}

A tradição do Dia das Bruxas nasceu como um culto aos mortos, realizado na véspera do dia de todos os santos, no dia 31 de outubro, e foi levada aos Estados Unidos pelos irlandeses. Aos poucos, está sendo comemorado em muitos países.

Figura 10 - Dia das Bruxas

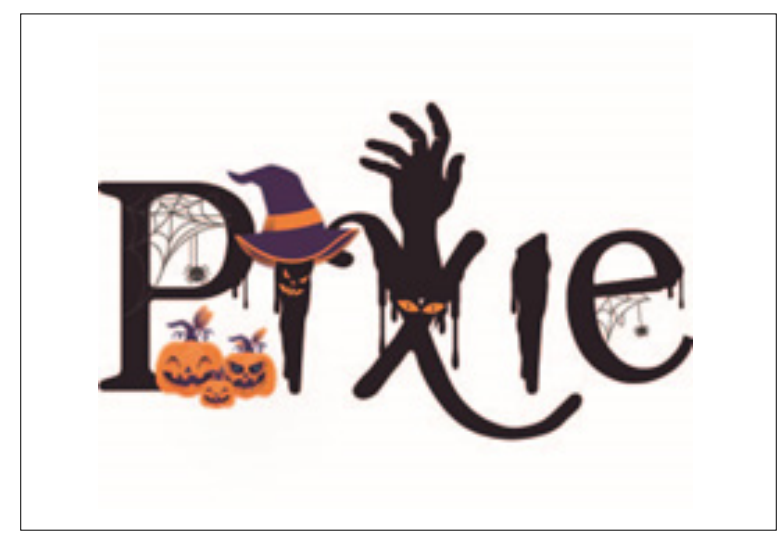

Fonte: Marcieli Hoffmann (2018) 


\section{Elementos místicos}

Contos de fadas. Esta coleção apresenta o lado místico da marca, sendo utilizados elementos presentes nos contos de fadas.

Figura 11 - Contos de fadas

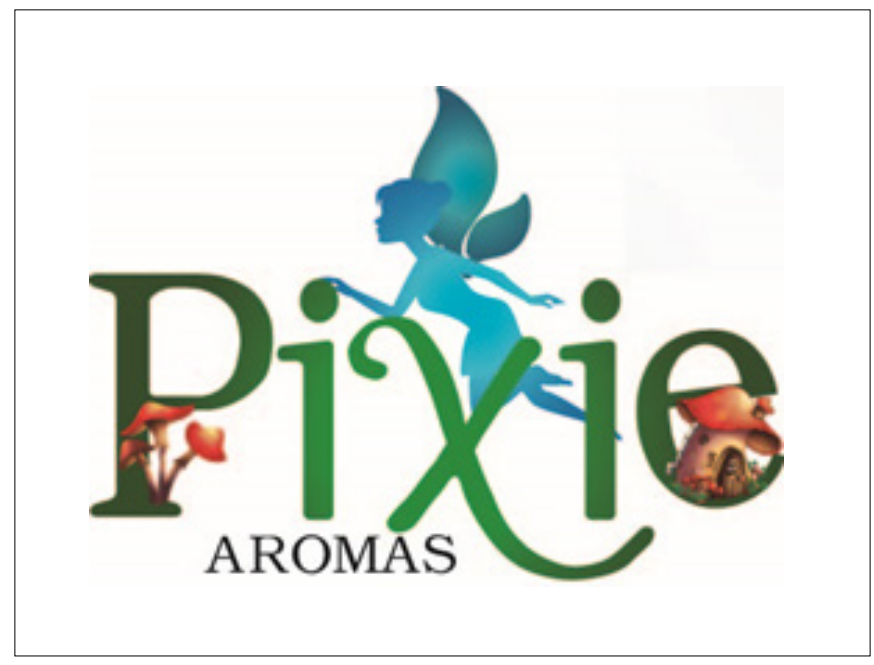

Fonte: Marcieli Hoffmann (2018) 


\section{Borboletas}

Conforme mencionado anteriormente, as borboletas representam a vida. Nessa versão, as borboletas se encontram em seu habitat.

Figura 12 - Borboletas

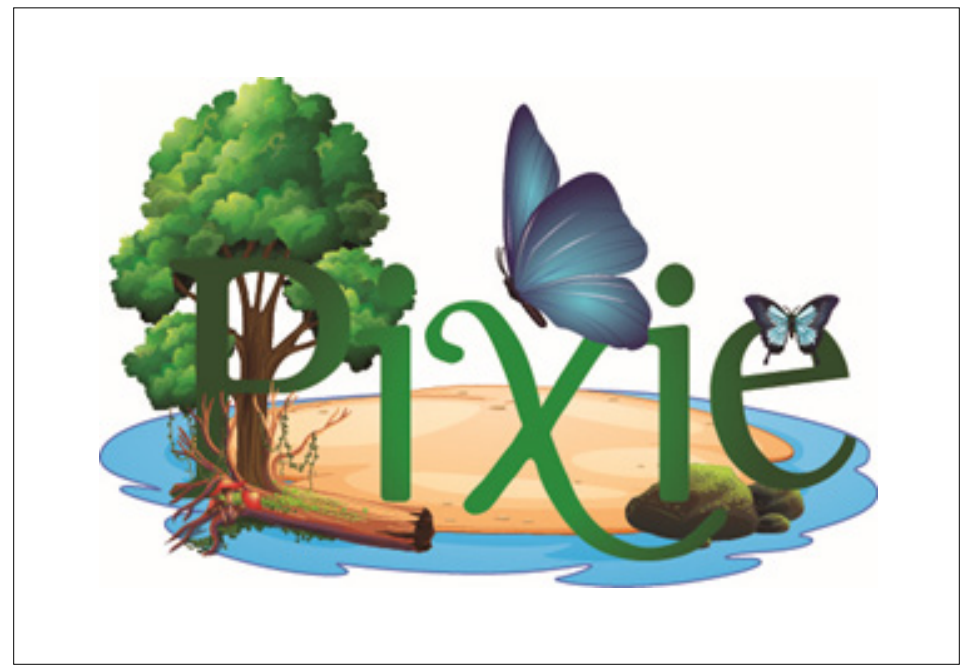

Fonte: Marcieli Hoffmann (2018)

\section{CONSIDERAÇÕES FINAIS}

O processo de construção e de desenvolvimento de uma marca é complexo e exige do profissional muito conhecimento e experiência em branding, no que se refere ao discurso multimodal da marca, comportamento e imagem-conceito, e em semiótica, no que tange aos símbolos e seus significados para representação da marca em sua identidade visual.

Uma marca cuja missão é despertar emoções através do olfato, exige ainda mais interesse profundo e conhecimento em sentimentos humanos associados à aromaterapia, às cores e aos comportamentos. Além disso, o próprio naming da marca conduz ao mágico. E para representar isso, traduzindo a essência da marca, foi necessário ir além das propostas convencionais de identidades visuais e adotar a estratégia de Marca Mutante, para mostrar ao consumidor (público) que a marca pode encantar não só pelo olfato, personalizando seu aroma, mas também pela visão, personalizando a identidade visual, permitindo que ele se identifique com a marca. Portanto, essa escolha para a Pixie Aromas honra sua essência. 
O presente estudo teve como objetivo geral descrever os processos de criação e de desenvolvimento de uma marca de aromatizantes para o mercado do Vale do Taquari/RS. Considerando que o processo de construção de marca é complexo e exige do profissional conhecimento (saber), experiência (saber fazer) e ética (saber ser), espera-se que o mesmo seja relevante para os profissionais da área, para os acadêmicos e também para os empresários, posto que apresenta os passos para a criação de uma marca real, a ser lançada no mercado em breve.

Sendo assim, será possível acompanhar dos resultados das estratégias adotadas, verificando se as mesmas foram assertivas ou se necessitam de ajustes para contribuir com o crescimento da marca. E, desta forma, abre oportunidades para novos estudos. Como sugestão de pesquisa futura, propõese averiguar quais estratégias de branding contribuíram com a consolidação da marca Pixie Aromas no mercado do Vale do Taquari.

\section{REFERÊNCIAS}

BALDISSERA, Rudimar. IMAGEM-CONCEITO: A INDOMÁVEL ORGIA DOS SIGNIFICADOS. Disponível em: <http://www.intercom.org.br/papers/nacionais/2003/www/pdf/2003_NP05_baldissera.pdf>. Acesso em: 3 ago. 2018.

BIEDERMANN, Hans. Dictionary of Simbolism. New York: Meridion, 1994.

BRINGHURST, Roberto. Elementos do estilo tipográfico (versão 3.0). São Paulo: Cosac Naify, 2005.

BUENO, Rosângela Aparecida; NEVES, Rosângela Domaneschi. Cliente Oculto: técnica de pesquisa e avaliação de atendimento. 2008. Disponivel em: http://intertemas.unitoledo.br/revista/index.php/ETIC/ article/viewFile/1795/1706 Acesso em: 25 dez. 2017

Design Culture. 0 que são fontes TrueType, OpenType e PostScript? Disponivel em: <https://designculture.com.br/o-que-sao-fontes-truetype-opentype-e-postscript>. Acesso em: 2 out. 2018.

FARKAS, Fátima L. Marketing olfativo: um guia para aromatização de ambientes. São Paulo: Editora Senac, 2013.

Fonts2u. Disponivel em: <https://fonts2u.com/angleterre-book.font>. Acesso em: 29 ago. 2018.

GIL, Antonio C. Métodos e técnicas de pesquisa social. 6 Ed. São Paulo: Atlas, 2011. 


\section{Gestãoe \\ Desenvolvimento}

e-ISSN: 2446-6875

p-ISSN: 1807-5436

GOBÉ, Marc. A emoção das marcas: conectando marcas as pessoas. Rio de Janeiro: Campus, 2002.

GOBÉ, Marc. Brandjam: o design emocional na humanização das marcas. Rio de Janeiro: Rocco, 2010.

KELLER, Kevin L; MACHADO, Marcos. Gestão estratégica de marcas. São Paulo: Pearson Prentice Hall, 2006.

KOTLER, Philip. Administração de marketing: análise, planejamento, implementação e controle. 2. ed. São Paulo: Atlas, 1992.

KREUTZ, Elizete A; FERNANDEZ, Francisco J. M. Branding e as tendências da comunicação mercadológica. In: LUSOCOM, Lisboa: 2009.

KREUTZ, Elizete. A Construção de Marcas Mutantes. In: Chasqui. Quito: Equador, 2012. No. 119.

KREUTZ, Elizete. Identidade Visual Mutante: uma Prática Comunicacional da MTV. Porto Alegre: FAMECOS, 2005.

As principais estratégias de construção da Identidade Visual Corporativa. Porto Alegre: PUCRS, 2001. (Dissertação).

Marcas Mutantes Na América Latina. In: Revista Brandtrends, ed. 01. Lajeado, Brasil: UNIVATES, 2011.

LEI No 9.279, DE 14 DE MAIO DE 1996. Presidência da República - Casa Civil. Disponível em: <http:// www.planalto.gov.br/ccivil_03/Leis/L9279.htm>. Acesso em: 20 set. 2018.

LINDSTROM. Martin. Brandsense: segredos sensoriais por trás das coisas que compramos. Porto Alegre: Bookman, 2012.

LINDSTROM, Martin. Brandwashed: lado oculto do marketing: controlamos o que compramos ou são as empresas que escolhem por nós. São Paulo: HSM, 2012.

INPI, Instituto Nacional da Propriedade Industrial. Manual de Marcas. Disponivel em: <http://manualdemarcas.inpi.gov.br/projects/manual/wiki/02_O_que_\%C3\%A9_marca\#2-0-que-\%C3\%A9-marca>. Acesso em: 22 ago. 2018.

MARK, Margaret; PEARSON, Carol. O herói e o fora-da-lei: como construir marcas extraordinárias usando o poder dos arquétipos. São Paulo: Cultrix, 2016.

MARTINS, José R. Branding. Um manual para você criar, gerenciar e avaliar marcas. $3^{a}$ Ed. São Paulo: Global Brands, 2006. 


\section{Gestãoe \\ Desenvolvimento}

e-ISSN: 2446-6875

p-ISSN: 1807-5436

NEUMEIER, M. The Brand Gap. 0 abismo da marca. Porto Alegre: Bookman, 2008.

Olfato, oído, gusto - Los sentidos de las marcas no tradicionales. Organización Mundial de La Propriedad Intelectual (OMPI). Disponível em: <http://www.wipo.int/wipo_magazine/es/2009/01/article_0003.html>. Acesso em: 18 out. 2018.

PENN, Gemma. Análise Semiótica de imagens paradas. In: BAUER, Martin; GASKELL, George. Pesquisa Qualitativa com texto, imagem e som: um manual prático. Petrópolis: Vozes, 2002.

REGISTRO.BR. Pesquisa da marca Pixie Aromas. Disponivel em: <https://registro.br> Acesso em: 23 ago. 2018.

REYMAN, Joey. Propósito. Por que ele engaja colaboradores, constrói marcas fortes e empresas poderosas. São Paulo: HSM Editora: 2013

RODRIGUES, Delano. Naming, o nome da marca. 2ª Ed. Rio de Janeiro: 2AB, 2013.

SABRINA, Lady. 0 grande livro de magia da bruxaria Grimoire. 5ªEd. São Paulo: Madras, 2016.

SALTZ, Ina. Design e tipografia: 100 fundamentos do design com tipos. São Paulo: Edgard Blücher, 2010.

SILVESTRE, Carminda. et.al. O Discurso da Marca: o caso Natura e NaturaPura. In: VIII Congresso LUSOCOM. Lisboa: Lusófona, 2009.

STUMPF, Ida Regina C. Pesquisa bibliográfica. In: DUARTE, Jorge. BARROS, Antônio. Métodos e técnicas de pesquisa em comunicação. São Paulo: Atlas, 2006.

THOMPSON, John. Ideologia e cultura Moderna. Petrópolis: Vozes, 1995.

TROIANO, Jaime. Brand Intelligence. 1ª Ed. São Paulo: Estação das Letras e Cores, 2017.

YAMAOKA, E. J. O Uso da Internet. In: DUARTE, J. BARROS, A. Métodos e técnicas de pesquisa em comunicação. São Paulo: Atlas, 2006, p. 146 a 162. 